\title{
THE EFFECTS OF MOBILE VIRTUAL LABORATORY USE TOWARDS STUDENTS' METACOGNITION IN PRACTICUM LEARNING
}

\author{
Manikowati \\ Unit of Multimedia Development for Education and Culture \\ Balai Pengembangan Multimedia Pendidikan dan Kebudayaan, Kemdikbud \\ Jl. Mr. Koessoebiyono Tjondro Wibowo, Pakintelan, Gunungpati, Semarang - \\ 50227 Email: manikowati@kemdikbud.go.id
}

\begin{abstract}
ABSTRACT: This study was to analyze the effects of using mobile virtual lab for students in practicum learning, especially those related to their metacognitionknowledge and regulation. The method used was qualitative research. To collect the data, three instruments were used-closed and opened questionnaires, observation sheets, and practicum worksheets. The data were obtained from 105 junior high school students from seven different schools in Semarang. The data obtained showed that the students' metacognitive knowledge worked well. They were very aware of the materials they learnt and the strategy in doing their practicum. During using it, they could monitor and control their cognition. By using the practicum worksheet, they could know their comprehension of the practicum they did because the application directly showed the result of their experiments. When their experiment succeeded, they looked happy and shared their success with other friends. On the contrary, when they had a doubt with their experiments, they would read the worksheet again slowly and repeat their practicum. Even, they sometimes asked their teacher for guidance. To show their practicum performance, they noted the result in the worksheet. After checking their worksheets, it was found that there were 9 out of 105 students who could not do their practicum well. From this study, it can be concluded that the use of mobile virtual laboratory could give more favorable effects to the students' knowledge and regulation metacognition in their practicum learning. Therefore, it is suggested that teachers and students use this model in the practicum learning.
\end{abstract}

Keywords: Mobile, Learning, Virtual, Laboratory, Junior High School 


\section{INTRODUCTION}

Unit of Multimedia Development for Education and Culture, or so-called Balai Pengembangan Multimedia Pendidikan dan Kebudayaan, (BPMPK) is one of Ministry of Education and Culture's units whose main duty is to develop multimedia for education and culture. There are many models of multimedia for learning and culture being developed. One of them is mobile virtual laboratory for junior high school students.

Mobile virtual laboratory, for short called mobile v-Lab, is a kind of learning multimedia being developed to overcome a laboratory capacity problem. Based on the data from the Ministry of Education and Culture (2017), there are only 6.966 out of 23.375 labs which are feasible. It means that 16.409 labs are out of order, which means that they cannot be used properly for the students in practicum learning. Therefore, the existence of mobile virtual laboratory is very helpful for them. They can do their practicum wherever dan whenever without going to a real laboratory.

Doing the practicums anytime and anywhere is possible because the application is accomplished by practicum worksheets. The application serves as the instruments and the materials for conducting the experiment. While the students are doing the practicum, they can use the worksheets. In the application, users can find usage information which enables them to operate it. Not only can they find the usage information, but they can also find the experiment information. The users are given guidance how they operate the materials in the application. However, there are only a few theories to stimulate them towards the experiment materials. In addition, in these worksheets is a step-by-step guidance for the users to do their practicum.

In regards with the model, it is assumed that the users' metacognition, either the knowledge or regulation, will work well. Flavell (1979) in Lai (2011) stated that metacognition is thinking about thinking. Metacognition knowledge is about thinking how somebody knows about his/her own cognitive and what factors influencing his/ her performance. Then, he/ she tries to know what strategy/ies he/she must take and why and when he/she will apply the strategy/ies. Meanwhile, metacognitive regulation is how somebody monitors his/her cognition and performance, has awareness of his/ her comprehension and task performance, and evaluates his/ her 
effectiveness of the applied strategy/s. Based on the definition above, it can be concluded that metacognition is thinking about cognitive knowledge and strategy.

There are some studies about metacognitive which had been carried out. Cera, Mancini, and Antonietti (2013) found that there were relationship metacognition, selfefficacy, and self-regulation. They stated that self-regulation is linked to metacognitive skills, like, planning, monitoring, evaluation, and concentration. And then, these skills influenced the students' efficacy in learning. Habibian (2015) showed that by implementing the cognitive strategy, the learners' reading ability enhanced significantly. Amin and Sukestiyarno (2015) also found the positiveness of metacognitive and cognitive skills, particularly in mathematics. Due to the benefits acquired by implementing metacognition, it is very advisable that this learning approach be carried out continuously.

There are also some studies which make use of metacognition using media. Chun and Hsiu (2011) developed metacognitive skills by using web-based media. They found that the students' scores increased after developing their metacognitive skills by using the web-based media. Hutauruk (2016) found that by using metacognitive cards containing some mathematic questions dealing with the class topic, the students developed metacognitive awareness to find their own strategy to remember and organize the information to solve the problems. Moreover, the students were used to monitoring, controlling, and evaluating their activities. From those studies, it can be seen that media, web-based and card play an important role in developing the students' metacognition. Therefore, it can be assumed that the students' metacognition will also be enhanced by using mobile v-Lab including in a practicum learning.

Based on the assumptions above, the researcher tried to analyze the effects of mobile v-Lab towards the students' metacognition in their practicum learning. She wants to know whether mobile v-lab has the desired results or not. Later, she will investigate more about the students' cognitive knowledge and regulation components. Regarding with cognitive knowledge, she will focus on the students' awareness of materials they study and the strategy they choose. While for the cognitive regulation, she will focus on the way the students monitor and control their learning while doing their practicum. 


\section{LITERATURE REVIEW}

Mobile Virtual Laboratory

This multimedia-based learning model is also called Mobile Virtual Laboratory or for short, mobile v-lab. This name actually derives from the term mobile, virtual, and laboratory. Mobile means easy to move. Oxford Dictionary (2018) defines mobile as able to move or be moved freely or easily, relating to mobile phones, handheld computers, and similar technology, able or willing. Dealing with this model, the term mobile means being able to be moved because the application is applied by handheld devices such as a mobile phone or a tablet. Then, virtual is defined as not physically existing as such but made by software to appear to do so (Oxford Dictionary, 2018). According to this definition, the content inside does not exist in reality. It is represented when using the application. Lastly, Oxford Dictionary (2018) defines the word laboratory or lab as a room or building equipped for scientific experiments, research, or teaching, or for the manufacture of drugs or chemicals. Based on the definitions above, Mobile Virtual Laboratory is a learning model implemented just like doing a real scientific experiment by using handheld devices.

The mobile v-lab developed by Unit of Multimedia Development for Education and Culture (Balai Pengembangan Multimedia Pendidikan dan Kebudayaan, or BPMPK) is a learning model integrated with multimedia for facilitating the students to make an experiment and exploration in order to improve a learning precision by using a mobile gadget (Manikowati, et al.; 2018). This model is being developed since 2016. Up to now, there have been twelve applications that can be used by teachers and students in a practicum learning. All of the applications can be downloaded from the website, m-edukasi.kemdikbud.go.id.

This model has two main components, which are the application as the equipment of the scientific experiment and the practicum worksheet. As the practicum equipment, the application is completed with an operating manual, a practicum usage manual, and an experiment area. The operating manual is to guide the users how to operate the application. It is equipped with the description of the icons in the application. The practicum usage manual is given to inform which competency is achieved, to guide the users how to operate the experiment area, and to inform them what they should do while doing the experiment. Meanwhile, the 
practicum worksheet is a document given separately from the application. The format of this worksheet is pdf. Therefore, if necessary, the users can download it and use it along with using the application. This worksheet functions as the practicum guidelines. There are necessary theories dealing with the experiment being practiced, the steps of doing the practicum, and the enrichment questions to help students gain the learning precision. These two components of mobile virtual laboratory are not separated in their practicum learning (Manikowati and Iskandar, 2018).

Metacognition

Metacognition comes from the word "meta" and "cognition". Meta according to Online Cambridge Dictionary (2018) means outside the normal limits of something while cognition means the use of conscious mental processes. Therefore, metacognition means outside use of conscious mental processes. It means that the process is not only a process of memorizing or thinking, but it is also how to think about cognition.

Metacognition was firstly introduced by John Flavell (1979). Flavell in Lai (2011) defined metacognition as thinking about thinking. He further explained that metacognition made someone know their cognition and which learning strategy to be applied. Furthermore, it also helps how someone works and his awareness of the task performance. Beamon (2001) defined metacognition as a powerful phenomenon that enables students to set goals, plan, solve problems, monitor progress, and evaluate their own thinking effectiveness. It provides the means for adolescents to oversee thinking as it happens, to determine what they know, to appraise what they need to know, and to orchestrate what they should do in a learning situation. Similarly, Ormrod (2006) defined metacognition as the ability to understand what we know, how we learned what we know, and how we manage and regulate or adjust our own thinking processes to maximize learning and memory.

Based on the definitions above, it can be seen that there are two main components of metacognition-metacognitive knowledge and metacognitive regulation. Lai (2011) describes metacognitive knowledge as a knowledge how someone or learner knows about his/her own cognitive and what factors might influence it (declarative knowledge), his/her learning strategy (procedural 
knowledge), and when or why he/she uses it (cognitive knowledge). Meanwhile, metacognitive regulation is an activity to plan, monitor, and evaluate (Lai, 2011). Panning activity is how a learner identifies and selects the appropriate learning strategies. Monitoring is an activity to attend and be aware of comprehension and task performance. Finally, Evaluating is an activity to regulate someone's learning processes. Lai (2011) later schemes the components into the following table. Table 1. Metacognitive Components

\begin{tabular}{|c|c|c|}
\hline Components & Descriptions & Outputs \\
\hline \multirow[t]{8}{*}{ Cognitive Knowledge } & Knowledge about oneself as & Person and \\
\hline & a learner and factors & knowledge \\
\hline & affecting cognition & Self-appraisal \\
\hline & & $\begin{array}{l}\text { Epistemological } \\
\text { understanding }\end{array}$ \\
\hline & & Declarative knowledge \\
\hline & Awareness and & Procedural knowledge \\
\hline & $\begin{array}{l}\text { management of cognition, } \\
\text { including knowledge about } \\
\text { strategies }\end{array}$ & Strategy knowledge \\
\hline & $\begin{array}{l}\text { Knowledge about why and } \\
\text { when to use a given strategy }\end{array}$ & Conditional knowledge \\
\hline \multirow[t]{4}{*}{ Cognitive regulation } & $\begin{array}{l}\text { Identification and selection } \\
\text { of appropriate strategies and } \\
\text { allocation of resources }\end{array}$ & Planning \\
\hline & Attending to and being & Monitoring or regulating \\
\hline & $\begin{array}{l}\text { aware of comprehension } \\
\text { and task performance }\end{array}$ & Cognitive experiences \\
\hline & $\begin{array}{l}\text { Assessing the processes } \\
\text { and products of one's } \\
\text { learning, and revisiting and } \\
\text { revising learning goals }\end{array}$ & Evaluating \\
\hline
\end{tabular}

(Lai, 2011) 


\section{METHODOLOGY}

The method used in this research was qualitative. The researcher investigated the data, identified them, and analyzed them. The results of the data, afterwards, were presented through graphs. Then, she interpreted the data and described the results.

Before investigating the data, the researcher did the followings. First, she prepared the instruments used to collect the data. Second, she tested the instruments for their validity and reliability. Finally, she determined the respondents.

In this study, there are three instruments-close-ended and open-ended questionnaires, observation sheets, and practicum worksheets. Close-ended and open-ended questionnaires are used to gain data about the students' cognitive knowledge. Observation and practicum worksheets are used to get the data of their cognitive regulation.

In testing the instruments, the researcher opted to use a test and a re-test. Regarding with the questionnaires and worksheets, she firstly gave the instruments to some junior high school students. She asked them to fill out the instruments. She, later, omitted the ambiguous items or refreshed them with the more acceptable ones. Finally, she retested the revised instruments. Meanwhile, the observation sheet was examined by some people working in educational technology.

The researcher used random purposive sampling when determining the respondents. Although she chose the students randomly, she still considered the students' grade in accordance with the prototypes which were going to be used. Moreover, she divided the number of the students equally. The research took place in seven junior high schools in Semarang.

The data gathering process took place from August $21^{\text {st }}$ to $29^{\text {th }} 2018$. While doing so, the researcher conducted a practicum teaching. In the initial process, she gave the apperception to the students. She tapped the students' knowledge by asking some questions dealing with the materials they would go through during the experiment. Then, she asked them about the difficulty of the material. She, then, explained the material they would do, the goals they would achieve, the device and mobile v-lab they could use, and how much time they had. The research made 
observations while the students were doing the practicum. After the students finished doing their practicum, the researcher asked them to fill out the questionnaires.

The following step was to identify the data. In this phase, she eliminated data which were not related to the research. The data were then grouped based on the category they belong to, i.e. the learning awareness or the strategy. Supporting photos and videos which were taken during the experiment were selected. Finally, she checked the students' worksheets and grouped the students into those who succeeded in their practicum and those who did not.

The final step was to analyze the data. In analyzing the data, the researcher used a descriptive analysis by using the presentation and narrative explanations. She presented the data through graphs and or tables.

\section{RESULTS AND DISCUSSION}

The followings are the results of the research. The first is about the students' cognitive knowledge. The other is about their cognitive regulation. There were two components of the cognitive knowledge which were found in the study---the students' learning awareness and their learning strategy. Meanwhile, in the case of the cognitive regulation, the researcher also found two components-monitoring and controlling.

There were five focuses dealing with the students' learning awareness. They were about the students' knowledge of the material being experimented, the difficulty of the material, the time to comprehend the material, the learning software and hardware needed, and the concentration for learning the material.

The chart below shows the students' knowledge of the material:

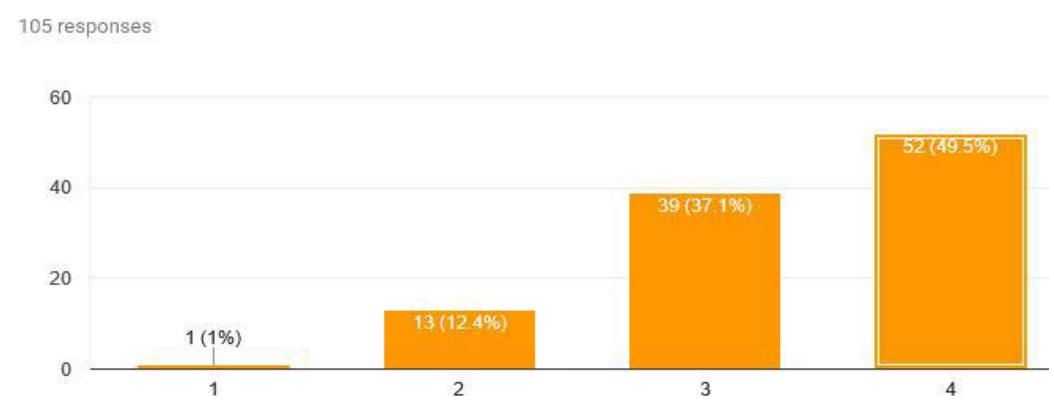

Figure 1. Students' Knowledge of Material 
Based on the above chart, we can see that there was $49.5 \%$ of the students who understood the materials very well and $37.1 \%$ who fairly understood the materials. $12.4 \%$ who less understand and $1 \%$ who did not understand at all. Let's say that $50 \%$ is the median of the range, then it can be said that $86.6 \%$ of the students understood the materials. It means that most of the students understood the materials they learnt.

When focusing on the materials of experiment, it is found that there was $36.2 \%$ of the students who had difficulty comprehending the materials and $30.5 \%$ who stated the materials were very difficult. There was $66.7 \%$ of the students facing difficulty in comprehending the material and just 33.4\% who stated that it was not difficult. The explanations above is described in the following chart.

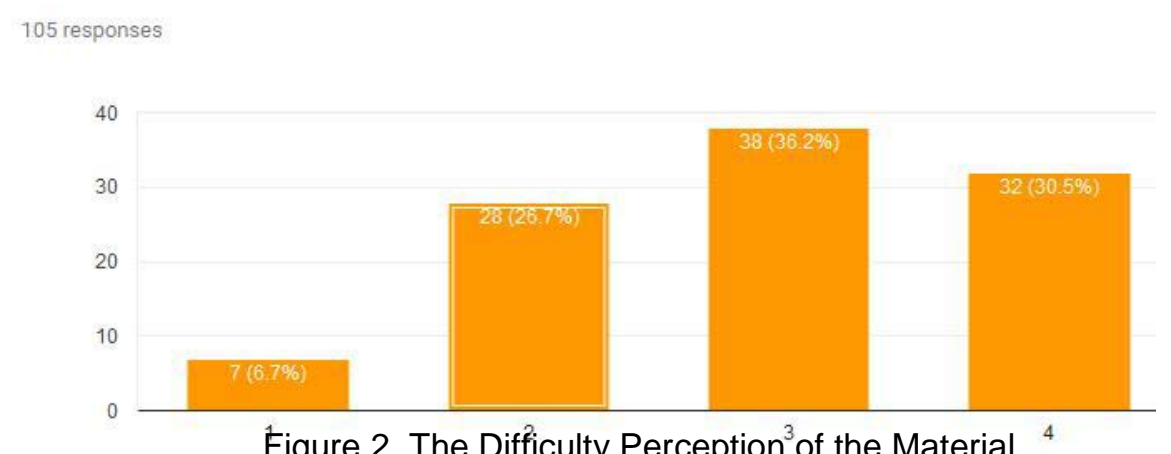

From the figure above, we can see that it is important for the students to have sound understanding about the materials. One of the strategies that a teacher can apply is through practicum learning.

Considering the students' difficulty, most of them (80\%) thought that they needed more time to comprehend the materials. Even, $86.6 \%$ of the students claimed that they also needed media to facilitate them during their practicum learning. Not only do they need media for learning, but they also need to concentrate when doing it. This condition is stated by $87.6 \%$ of the students. Therefore, there are three items the students needed to support their practicum learning. They are time, media, and concentration.

In short, in case of the students' awareness of learning, the students are fully aware of the materials being learnt. They thought that the materials were so difficult that they thought that the appropriate strategy to occupy the materials is through 
practicum learning. However, they still needed time, media, and concentration to help them.

Dealing with the students' learning strategies, there are two supporting components, i.e. the way they arranged and the time they did their steps in their practicum learning.

The data collected showed that there was $41.9 \%$ of the students who formulated steps in learning. Interestingly, $44.8 \%$ of them stated that they formulated their steps before learning. The remaining students mentioned that they did not really do so. It is described in the figure below.

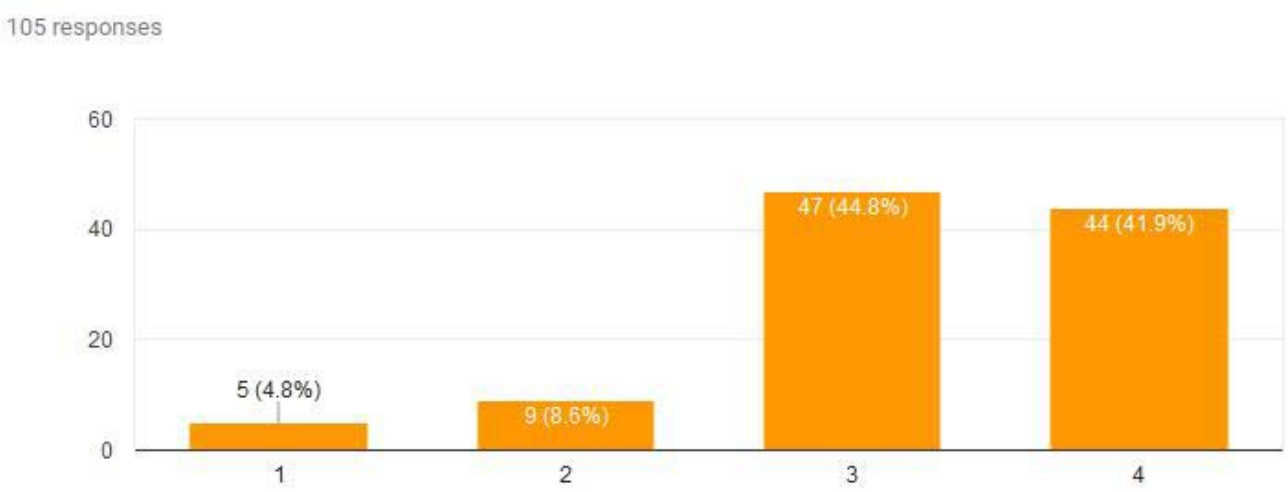

Figure 3. Learning Steps Formulation

As we can see from the chart, most of the students (86.7\%) formulated their steps before practicum learning. The following table shows the students' strategy/ies they formulated before and while doing the practicum.

Table 1. The Students' Strategy in the Practicum Learning

\begin{tabular}{|c|l|l|}
\hline No. & \multicolumn{1}{|c|}{ Strategylies } & Quantitylies \\
\hline 1 & Listening to the teacher's instruction & 1 student \\
\hline 2 & Preparing the device & 2 students \\
\hline 3 & Preparing the practicum worksheet & 2 students \\
\hline 4 & Installing the application & 8 students \\
\hline 5 & Reading the theory & 15 students \\
\hline 6 & Reading the manual & 17 students \\
\hline 7 & Reading the practicum steps & 22 students \\
\hline
\end{tabular}


From the above table, we can see that 67 students attempted to formulate strategy/ies before or during the practicum learning. Meanwhile, other 38 students stated they applied common strategy/ies of learning, like praying before learning. The remaining number of students did not really serve as supporting data, which were then omitted. The data obtained in this case show how they think when solving problems.

Beside being observed for their ability in formulating appropriate strategy/ies for the practicum learning, they are also observed for their ability in implementing appropriate time to apply the strategies. There was $43.8 \%$ of the students who could determine precisely when they must implement the strategies. In one hand, there was $38.1 \%$ of the students who just figured out when to implement them. On the other hand, there was $18.1 \%$ of the students who did not know when they must implement them. The following figure shows the how the students used time for implementing the learning strategy/ies.

105 responses

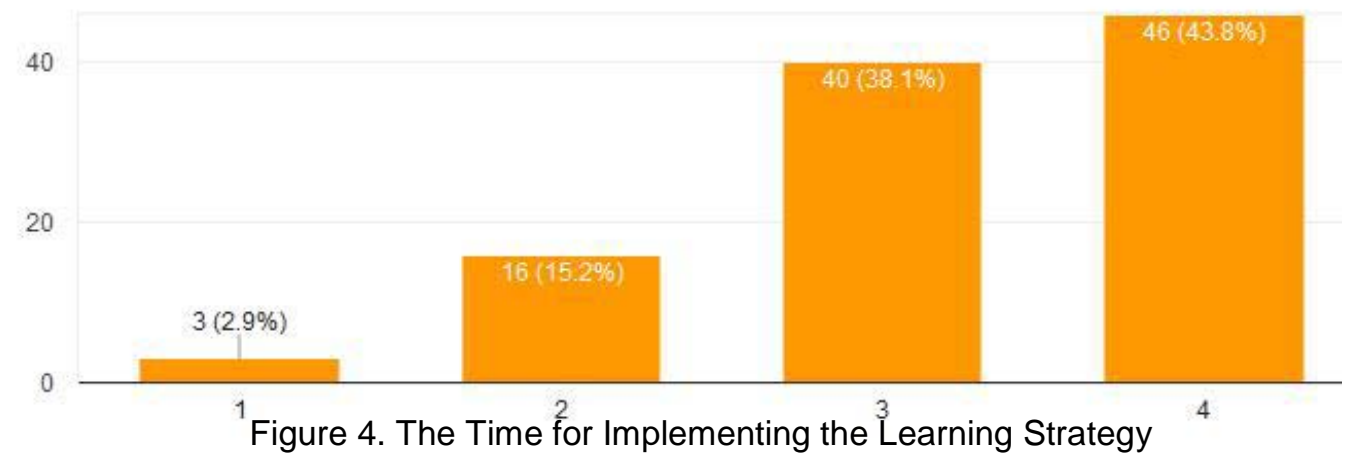

Based on the data above, we can see that most of the students had sound understanding about what they should do before doing their practicum learning. More importantly, they also could implement the strategy/ies at the appropriate time.

After analyzing the data, the researcher found that the students' metacognitive knowledge was well facilitated by the application of mobile virtual laboratory. It was confirmed when observing their learning awareness-knowing their difficulty, the time needed, the media facilitated, and the concentration needed. Not only does the mobile virtual laboratory develop the students' learning awareness, but it also develops the students' learning strategy. It can be seen when they can formulate the 
strategies before doing their practicum learning and the time when they should execute them.

There were two observable components dealing with the students' metacognitive regulation. They were the students' learning monitor and their control. The followings are the results of the observation.

Using the practicum worksheet, the students were able to follow every step in their practicum. The students conducted the experiment using the application. Because the application showed immediate results of their experiments, they were able to monitor their own comprehensions toward the materials being experimented. When their experiment succeeded, they looked happy and shared their success with other friends. On the contrary, they showed desperation like scratching their head and tried to find somebody else to confirm their answers when they had doubt with their experiments. Those were some of the descriptions of how they monitored their practicum.

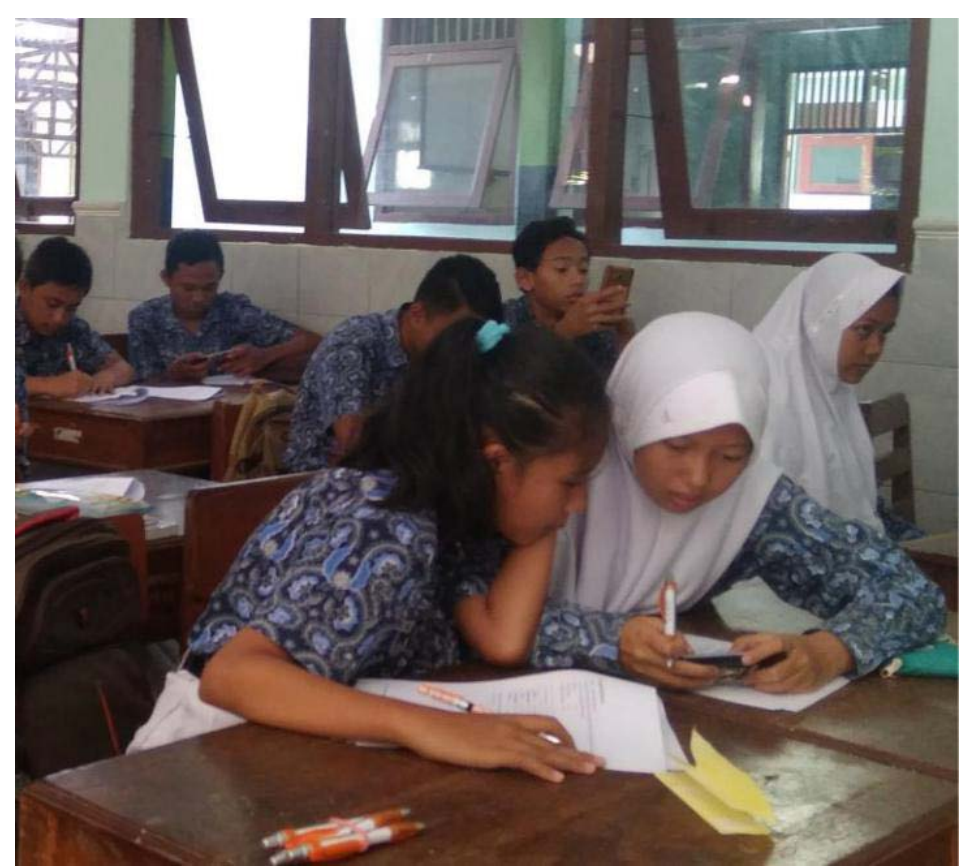

Picture 1. Students Retried their Experiment Together 


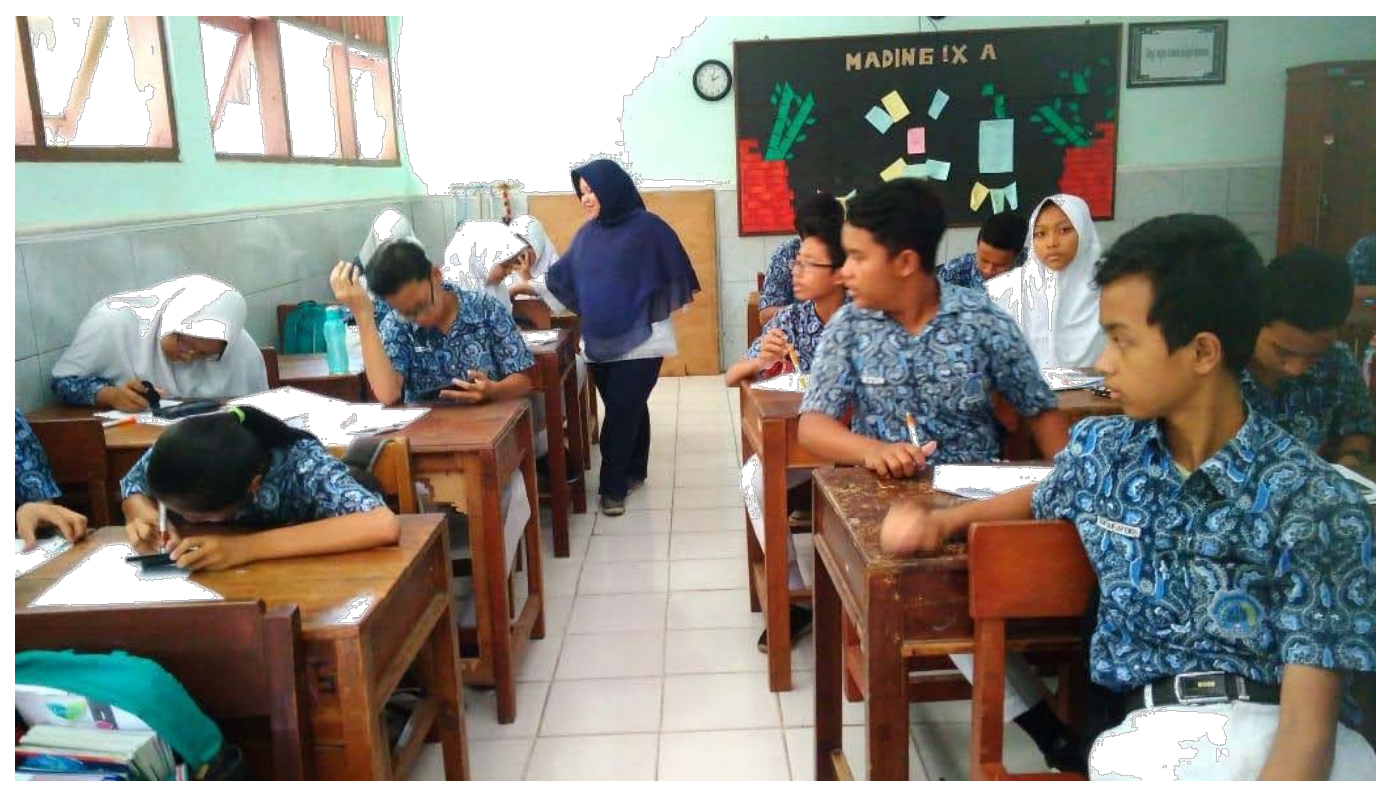

Picture 2. One of Students Scratched his Hair and Grabbed his Friends looked at him

In case of controlling their cognition, these were some of the solutions they made. First, they would read the worksheet again slowly and repeat doing their practicum. They sometimes collaborated with other students to redo their practicum. Even, sometimes they asked their teacher for guidance. By using the application, they could conduct the practicum over and over again until they succeeded. By using the practicum worksheet, they could control the way they conduct their practicum. In this regard, the mobile virtual laboratory was found to give positive impact for the students' metacognitive regulation in their practicum learning.

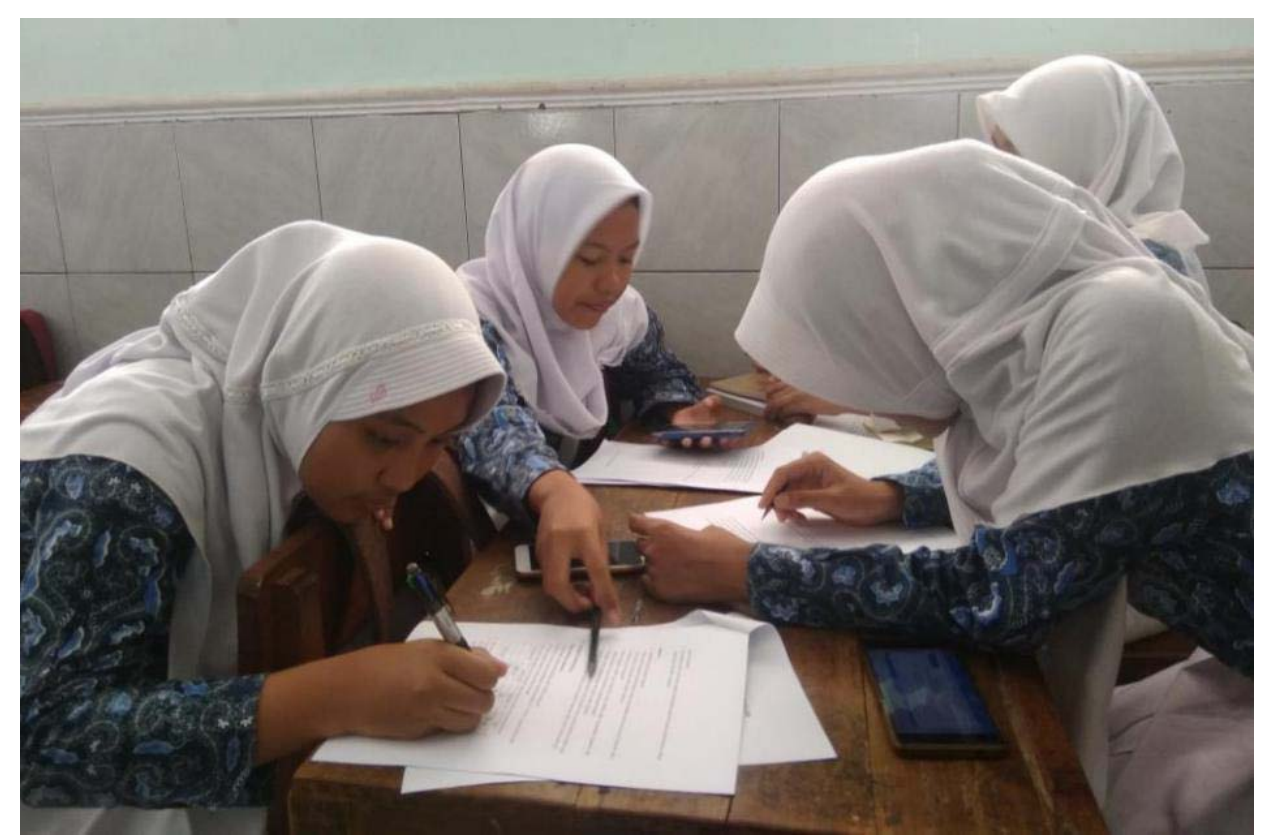

Picture 3. Students Tried to Solve the Practicum but Sometimes Asked to the Other 


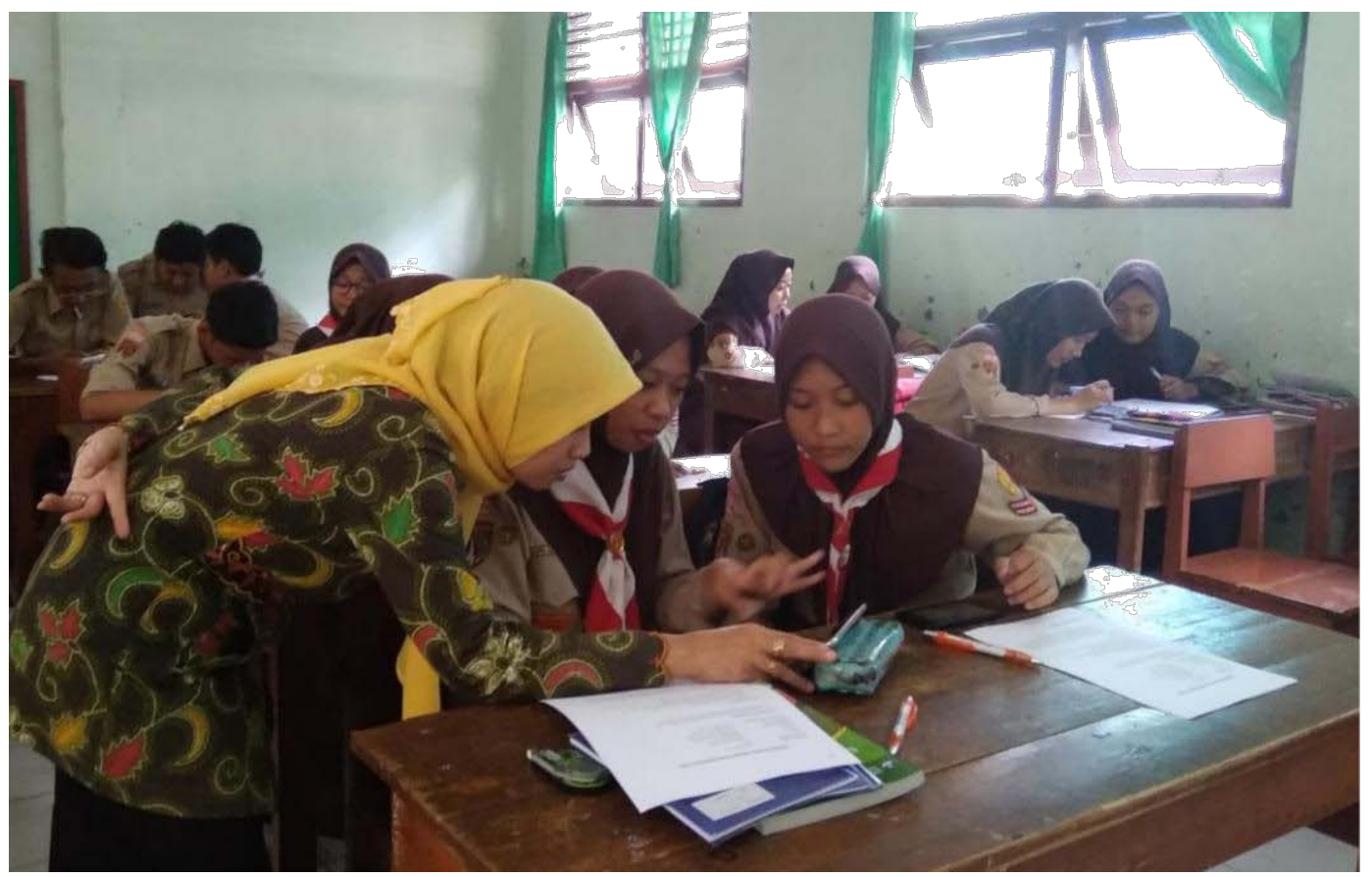

Picture 4. Students Collaborated with Friends and Asked to their Teacher

The third data resource was obtained from the practicum worksheet. After identifying each student's practicum result, it was found that there were nine students unable to succeed conducting their practicum due to time constraint. On the other hand, the rest of the respondents could finish conducting their practicum within the allocated time and made a conclusion as the learning precision.

Considering the all data above, we can see that the mobile virtual laboratory had given good effects for the students to solve their own learning problem. It means that mobile v-lab had made them think about thinking, how they should be aware of the materials they had, the difficulty that they might face, and the needs that might be helpful. Beside the effects above, the students also could formulate strategy/ies to overcome their problem(s) through a practicum and complete the task within the allocated time. During their practicum, they monitored their own cognition toward the materials and controlled their own learning by asking and or collaborating with others.

\section{CONCLUSION AND SUGGESTION}

Based on the results of the research, it can be concluded that the use of mobile virtual laboratory being developed by Multimedia Development Unit for Education and Culture had great effects dealing with the students' metacognition of Junior High School. The students could employ their metacognitive knowledge well. It could be 
seen from both their learning awareness and strategy. During the practicum, the students also demonstrated that they could monitor and control their own learning. They exhibited some expressions when they experimented and how they asked and collaborated with others were some proofs how they could successfully apply their metacognitive regulation.

Despite the results above, the researcher come up with some follow up suggestions. It is advisable that both the teachers and students use mobile virtual laboratory in the teaching and learning process, especially during the practicum learning. Due to its beneficial impacts in enforcing the students to have higher order thinking skill, it is better for the teacher to implement the mobile virtual laboratory during the learning process. Also, it is suggested for Unit of Multimedia Development for Education and Culture (BPMPK) to produce qualified applications and worksheets which can better facilitate the practicum process. Finally, it is highly recommended that BPMPK make an official cooperation with the other general directories of Indonesian Ministry of Education and Culture dealing with the mobile virtual laboratory dissemination. By doing so, it is hoped that there will be a good circle in developing mobile virtual laboratory. It starts from the teachers and the students and ends with them also.

\section{REFERENCES}

Amin, I. and Sukestiyarno. (2015). Analysis Metacognitive Skills on Learning Mathematics in High School. International Journal of Education and Research Vol. 3 No. 3. Retrieved September 2018 from www.ijern.com/journal/2015/March-2015/18.pdf

Beamon, Glenda Ward, (2001). Teaching with adolescent learning in mind. Glenview, III: Skylight Professional Development.

Cera, R., Mancini, M., and Antonietti, A. (2013). Relationship Metacognition, SelfEfficacy and Self-Regulation in Learning. ECPS Journal Vol. 7. Retrieved September 2018 from www.ledonline.it/ECPS-Journal/allegati/ECPS-20137 Cera.pdf

Chun-Yi SHEN \& Hsiu-Chuan LIU. (2011). Metacognitive skills development: a webbased approach in higher education. Tojet vol. 11 2011. Retrieved September 2018 from www.researchgate.net

Habibian, M. (2015). The Impact of Training Metacognitive Strategies on Reading Comprehension among ESL Learner's. JEP Vol. 6 No. 28. Retrieved September 2018 from https://files.eric.ed.gov/fulltext/EJ1081318.pdf 
Hargrove, Ryan A. and Nietfeld, John L. (2001). The Impact of Metacognitive Instruction on Creative Problem Solving. Retrieved September 2018 from https://core.ac.uk/download/pdf/11456851.pdf

Hutauruk, Agusmanto. (2016). Pendekatan Metakognitif dalam Pembelajaran Matematika. $\quad$ Retrieved September 2018 from https://www.researchgate.net/publication/315837363 PENDEKATAN METAKO GNITIF DALAM PEMBELAJARAN MATEMATIKA

Lai, Emily R. (2011). Metacognition: A Literature Review. Retrieved September 2018 from https://images.pearsonassessments.com

Indonesian Ministry of Education. (2017). Statistik Pendidikan. Retrieved September 2018 from http://statistik. data.kemdikbud.go.id/index.php/page/smp

Manikowati, etc. (2016). Rancangan Model Mobile Virtual Laboratorium BPMPK:

Grand design. Semarang: Unpublished

Manikowati and Iskandar, Dody. (2018). Pengembangan Mobile Virtual Laboratorium untuk Pembelajaran Praktikum Siswa SMA. Jurnal Kwangsan Vol.

62018 DOI: 10.31800. Retrieved October 20, 2018 from https://jurnalkwangsan.kemdikbud.go.id

Ormrod, J. E. (2006). Educational psychology developing learners. 5th ed. Upper Saddle River, NJ. Pearson Educational Inc. 